\title{
EL EMERGIR EN LA LENGUA Y LA RESIGNIFICACIÓN DE EXPERIENCIAS: CONSIDERACIONES SOBRE EL PIBID EN LA FORMACIÓN REFLEXIVA DEL PROFESOR DE ESPAÑOL EN BRASIL
}

\author{
Ivani Cristina Silva FERNANDES*
}

- Resumen: El presente artículo tiene como objetivo discutir algunos aspectos de la formación reflexiva del profesor de lengua española en Brasil por medio de la resignificación de experiencias y del análisis de las huellas de la subjetividad en el lenguaje que el sujeto discursivo deja en la materialidad linguística. Como transfondo, se presenta tal discusión en el contexto de las intervenciones concebidas dentro de la dinámica del subproyecto "PIBID Letras Espanhol” en la "Universidade Federal de Santa Maria”. Guiado por las nociones de la Lingüística de la Enunciación y de la Filosofía de la Educación pensadas en la formación del profesor de E.L.E., se pretende defender la hipótesis de que el profesor-formador de futuros profesores debe involucrarse en experiencias que exijan la valoración de la formación teórica, la postura reflexiva y la actitud (co)responsable como forma de proponer soluciones para problemas recurrentes en determinados espacios educacionales.

- Palavras-clave: Profesor reflexivo. Enunciación. Español. PIBID.

\section{Introducción}

En sus orígenes, el verbo reflexionar (reflectere) alude a la noción de "volver hacia atrás", "curvarse", "retroceder", lo que, en el ámbito filosófico, significa examinar nuevamente una cuestión o un tema con el objetivo de aclarar algunos detalles. Según Schöpker (2010, p.207) al tratar del sustantivo correspondiente a tal verbo, la reflexión destaca el hecho del retorno al pensamiento:

Em certo sentido, é o ato de dobrar-se sobre si, de ser "dois", de pensar a si próprio, suas representaçôes, ideais, sentimentos. De fato, refletir implica uma duplicação, mas também, de modo mais usual, diz respeito à suspensão de um juizo mais assertivo a fim de melhor discernir as coisas, os acontecimentos, os atos etc. Em Locke, a reflexão

\footnotetext{
* UFMS - Universidade Federal de Santa Maria - Departamento de Letras Estrangeiras Modernas. Santa Maria - RS - Brasil. 97105-900 - icrisifer@gmail.com.
} 
termina por coincidir com a consciência, até porque também a consciência é entendida como uma dobra do ser, um "outro" em nós", ou simplesmente, ela é, tanto quanto reflexão, uma percepção que temos de nossas próprias operaçóes internas. Esse é, no fundo, o sentido que permanece na filosofia contemporânea [...].

Al considerar los procesos involucrados en el acto de reflexionar, es posible vislumbrar el porqué de este verbo se presentar en las discusiones sobre la formación del profesor, en especial, el de lengua extranjera. La profesión docente, como consideramos el ejercicio de la docencia en este trabajo, implica (o debería implicar) que el profesional se comprometa a repensar constantemente sus enfoques, su relación con los saberes, su modo de marcarse en la lengua extranjera y, consecuentemente, en la materna. En suma, es una postura y una práctica reflexiva. Además, de una manera amplia, es imprescindible educar su mirada hacia cómo él concibe el otro en un escenario tan multicultural, fragmentado y ambiguo en la época rotulada como pos-moderna.

Con todo, en este mismo escenario y alimentada por una búsqueda de resultados rápidos, vemos que existe una tendencia al inmediatismo en los hechos e interacciones, hecho que también se presenta en el cotidiano de las clases de lengua. Por otro lado, los varios cambios de las políticas públicas en el área de la Educación frecuentemente carecen de un debate profundizado entre todos los involucrados: gobierno, investigadores, gestores, profesores y la comunidad escolar en general. Uno de los ejemplos más fragrantes fue la repercusión de la Ley Federal n. 11.161/2005, que obliga la oferta de la lengua española en todos los establecimientos de Enseñanza Media de Brasil y la torna optativa en la Enseñanza Fundamental (de $6^{\circ}$ al $9^{\circ}$ año). Sin embargo, no hubo un análisis previo adecuado para que se discutiera cómo sería la implementación de la ley en las escuelas. Entre tantas cuestiones que se levantaron en el momento, una de las que tuvieron énfasis fue la formación del profesor

Como nos recuerda Perrenoud (2002, p.9), "o debate sobre a formação dos professores perde-se no labirinto dos mecanismos institucionais. Cada um passa a defender o seu território, sua relação com o saber e seus interesses". Cuando nos referimos a la formación del profesor, en particular el de lengua extranjera, debemos antes preguntarnos qué es ser un profesor de lengua extranjera (en Brasil) y cuáles características el profesional debería abarcar. Tales cuestionamientos les invita a que todos los involucrados elaboren sus perspectivas tanto en la rutina escolar como en los órganos representativos de ese colectivo. El investigador francés aún destaca que:

Trata-se de uma perspectiva a longo prazo, de um processo estrutural, de uma lenta transformação. Podemos ajudar a criar as condiçôes para a evolução; porém, nenhuma corporação ou nenhuma reforma pode provocá-la em um curto espaço de tempo, de forma unilateral. Entretanto, não poderá haver profissionalização do oficio de professor se essa evolução náo for desejada, desenvolvida ou sustentada continuamente por 
numerosos atores coletivos, durante décadas, para além das conjunturas e alternâncias politicas (PERRENOUD, 2002, p.9-10).

En ese panorama, ha sido ideado un proyecto institucional con el objetivo, por un lado, de valorar la docencia en sus orígenes, es decir, en los cursos de "Licenciatura" y, por otro, de vincular más directamente las acciones entre universidades y escuelas de enseñanza básica. Con estos propósitos, en 2007 fue creado el "PIBID - Programa Institucional de Bolsa de Iniciação à Docência”. En 2014, según presenta la página institucional de la "Coordenação de Aperfeiçoamento de Pessoal de Nivel Superior (CAPES)", tal programa abarcaba 313 proyectos, distribuidos en 284 instituciones de enseñanza superior y que asignaba un total de 90.254 becas (72.845 específicas para los alumnos de la 'Licenciatura').

A partir de 2009, la "Universidade Federal de Santa Maria" (UFSM-RS) ingresó en el programa, alcanzando 19 cursos de "Licenciatura" de los 20 existentes en la universidad. Entre tales cursos, el de Licenciatura Letras / Español está representado por un subproyecto. En 2014, a pesar de la variación durante el año, el grupo se constituyó por nueve alumnos de "Licenciatura" (que estaban entre el $3^{\circ}$ y el 9o semestres del curso), una profesora supervisora de la escuela de Educación Básica Profa Margarida Lopes (Camobi - Santa Maria) y una coordinadora del subproyecto, que también es profesora del curso de Letras / Español en el área de lengua española y del Postgrado en Letras. El subproyecto realizó actividades en los grupos de la Enseñanza Fundamental y Media, en que 165 alumnos fueron beneficiados.

Durante la experiencia, fueron el cerne de nuestro trabajo muchas indagaciones relacionadas a la esencia del profesor de lengua extranjera y cómo se (re)construye este esbozo. A partir de este trasfondo, nos gustaría reflexionar sobre los desafíos del trabajo de formación inicial de los futuros profesores de español como lengua extranjera para brasileños, en especial, cuando nos referimos a su posición de apropiarse de la lengua como sujetos a la vez que toman conciencia de su papel de guiar el otro en ese mismo camino. Por otro lado, con base en las nociones de la Lingüística de la Enunciación, pretendemos realizar un paralelo entre los procesos enunciativos y el de hacerse profesor, una vez que el individuo se enuncia como articulador de voces y surge en la materialidad lingüística de la lengua española y portuguesa entre el simulacro de la transparencia y la constancia de lo diferente. Y ese conjunto sorprende por la sutileza.

Disponível em: <http://www.capes.gov.br/educacao-basica/capespibid/pibid>. Acesso em: 20 dez. 2014. 


\section{Enunciar y enunciarse en español: ¿cómo hacerse sujeto en la lengua?, ¿cómo esbozar el ethos docente?}

Muchos paralelos ya se construyeron con la finalidad de explicar las características de un profesor de lengua extranjera, entre ellos, profesor interculturalista como nombró Serrani (2005). Según la investigadora, tal profesor es un perfil que:

[...] corresponde ao de um docente - de lingua materna ou estrangeira - apto para realizar práticas de mediaçáo sócio-cultural, contemplando o tratamento de conflitos identitários e contradiçóes sociais, na linguagem de sala de aula [...]. O perfil de interculturalista, sensivel aos processos discursivos, requer que o profissional considere especialmente, em sua prática, os processos de produçáo-compreensão do discurso, relacionados diretamente à identidade sócio-cultural (SERRANI, 2005, p.15-18).

A partir de las palabras de Serrani, destacamos que la posición del profesor de lengua, en particular el de lengua extranjera, debe ser la figura que está en el entremedio, es decir, el profesional que se propone a pensar en cómo las identidades fragmentadas y múltiples que surgen en cada discurso se enlazan y de qué forma. Desde luego, no es una actitud valorativa que busca una jerarquía entre las identidades, sino una postura reflexiva que busca analizar los puntos de junción y disyunción entre los discursos, las voces y las imágenes de los interlocutores en cada materialidad.

Ocupar el lugar de articulador de las discusiones y de las voces en el aula requiere antes que el individuo en formación como profesor consiga desarrollar ese papel consigo mismo y entre sus pares. Y, lo que nos parece más importante, cuestionar de qué modo su imagen discursiva surge en y por la lengua extranjera para que se pueda comprender los desafíos que los discentes enfrentan en marcarse en otra lengua, aunque no sean conscientes de ello.

Estamos de acuerdo con Revuz (1998, p.227) cuando destaca que el hecho de aprender una lengua extranjera implica hacerse otro, una vez que existen rupturas, descubiertas y apropiaciones. Hay que asumir el desconocimiento de sí y del otro como interlocutor y del Otro como elemento de la alteridad, de lo distinto que está en sí y que le permite esbozar quien es cada uno.

Ese preámbulo filosófico-discursivo nos acercar a nuestro eje de discusión: la necesidad de reflexionar sobre la emergencia de cada uno en la materialidad de la lengua extranjera y cómo ello puede resignificar experiencias. Entre los varios caminos que podemos elegir, nos hemos decidido guiar por las nociones de la Lingüística de la Enunciación, área en que se reúnen teorías que, por diferentes vías, discuten los procesos enunciativos.

En primer lugar, dos nociones importantes se refieren al acontecimiento y a la materialidad lingüística: la enunciación y el enunciado. La enunciación, según Benveniste (2006, p.82), es el "colocar em funcionamento a lingua por um ato individual 
de utilização" y, por consecuencia, es por medio de la enunciación que el sujeto se construye constantemente en cada momento único en que se apropia de la lengua y conforme las condiciones de producción y los géneros discursivos involucrados en este fenómeno.

Por otra parte, la enunciación deja sus huellas en la materialidad lingüística, su producto que reconocemos como enunciado (FLORES et al., 2009). Como enfatiza Fiorin (2005), el enunciado es el espacio en que el sujeto se revela y se marca. Es también en el enunciado que los mecanismos lingüísticos se articulan, sea en la modalidad oral, sea en la escrita. De ahí que destacamos que el profesor de lengua extranjera, en nuestro caso, el de español, debe desarrollar una mirada sensible hacia la lengua y su materialidad y buscar analizar sus sutilezas y articulaciones, sin olvidarse del universo del discurso en que se insiere la producción de tal materialidad. En definitiva, como enfatiza Kulikowski y González (1999, p.14), "lo dicho es inseparable del decir, no hay enunciados aislados, no se pueden trabajar actos de habla elementares en el sentido único, no se pueden enseñar / aprender enunciados independientes separados de la enunciación”.

Aunque la Lingüística de la Enunciación enfoque el sujeto del enunciado, una vez que observa "as marcas da enunciação do sujeito no enunciado" (FLORES, 2008, p.94), no podemos restringir la discusión en ese sujeto sin observar el de la enunciación: el docente y los discentes en la interacción. Son ellos los protagonistas en el sistema de enseñanza. Además, muchas de las transformaciones de postura podrán observar cuando este sujeto de la enunciación se convierte en el sujeto del enunciado en la materialidad en español.

En el caso del análisis de la lengua española en el contexto de los aprendices brasileños, estudiarla significa afrontar falsas transparencias y las generalizaciones extremas, muchas veces consecuencias del imaginario sobre el español y sobre las sociedades involucradas en los discursos en tal lengua. La desconstrucción y reconstrucción de los imaginarios y discursos son primordiales en la labor del profesor.

Al repasar las palabras de Kulikowski e González (1999) sobre la búsqueda de la "justa medida de una cercanía”, es importante enfocar que apropiarse del español es un proceso continuo de percepción de una nueva organización lingüística, un orden distinto de regularidades, un interdiscurso del otro en que sentidos distintos surgen en y por la lengua española. De ese modo, proponerse analizar las maneras distintas de estructuración fonético-fonológica, morfosintáctica y enunciativo-discursiva del español influye en la construcción de una perspectiva más crítica sobre la materialidad lingüística del portugués brasileño.

Para entender ese proceso de estar en el "entremedio" y vivenciarlo, el profesional en formación en la docencia del español necesita pensar el proceso enunciativo no sólo en la perspectiva lingüística estricta, sino reflexionar cómo él propio se enuncia en portugués y en español, esbozando un ethos (es decir, una imagen discursiva conforme determinados objetivos, interlocutores y condiciones de producción) que surge en la 
materialidad y se molda continuamente en el seno de las articulaciones de voces y de la intersubjetividad en el lenguaje. Es imprescindible pensar sobre las imágenes discursivas de los interlocutores, en que la voz de un "yo" implica la existencia de un "tú" como nos reza la noción benvenistiana de intersubjetividad.

No existe un único camino, tampoco una ruta o un manual para ser recurridos. Sin embargo, es importante formular algunas preguntas esenciales como las que mencionamos en nuestro subtítulo. De esa manera, si consideramos que enunciar es un acontecimiento individual en que se combinan la forma y el sentido, podemos concebir que enunciarse como profesor es combinar determinada perspectiva, postura y actitud con algunos sentidos de la emergencia de un ethos discursivo docente, es decir, la construcción discursiva de una imagen de ese locutor docente que tiene como finalidad influenciar sus interlocutores en determinado contexto de producción. Incluso, una de las maneras de entender la enunciación es concebirla como área que enfoca cómo el hombre y sus singularidades se presentan en el lenguaje y dejan sus huellas en la lengua.

Por otra parte, también es elemental saber trazar cuáles son las condiciones de producción y el contexto educacional en que el español será discutido, para que, posteriormente, podamos pensar qué tipo de imagen de profesor se quiere esbozar por medio de actitudes y posturas. Para mejor direccionar nuestra discusión, en el presente trabajo, vamos a restringir nuestros comentarios al contexto de la enseñanza pública básica, lo que no impide que las consideraciones aquí elaboradas puedan ser repensadas en otros espacios.

En la parte dedicada a la enseñanza del español de las Orientaçóes Curriculares para o Ensino Médio (BRASIL, 2006, p.129), observamos que tal documento pretende:

[...] proporcionar algumas reflexóes de caráter teórico-prático que nos levem a compreender um pouco mais os conflitos inerentes à educação, ao ato de ensinar, à cultura que consolida a profissão de professor, ao aprendizado de Linguas Estrangeiras e à construção de uma visão de mundo, para podermos, quiçá, melhor lidar com eles. Trata-se de uma reflexão de caráter amplo, que inclui alguns indicadores cuja finalidade é nortear o ensino de lingua estrangeira, nesse caso o Espanhol, no ensino médio, darthe um peso no processo educativo global desses estudantes, expondo-os à alteridade, à diversidade, à heterogeneidade, caminho fértil para a construção da identidade.

Queremos enfatizar en ese momento que, en la formación de los brasileños, el español no sería una lengua que debe servir a fines estrictamente comunicativos e inmediatistas, sino que es una lengua esencial para que se comprenda la diversidad y la multiplicidad de perspectivas existentes en la realidad en que vivimos, lo que implica el proceso de ponerse en el lugar del otro para poder entender el lugar de uno en la dinámica de esta realidad; es intentar dialogar con el Otro que existe en nosotros. Así, la enseñanza del español debe "levar o estudante a ver-se e constituir-se como sujeito a 
partir do contato e da exposição ao outro, à diferença, ao reconhecimento da diversidade" (BRASIL, 2006, p.133). En otras palabras, se pretende formar ciudadanos críticos y actuantes en una sociedad plurilingüe y multicultural. Por consiguiente, en el mismo documento, se concibe el profesor como actor que (re)construye saberes.

Con todo, creemos que se puede lograr esa meta si exponemos los futuros profesores a ese proceso de hacerse ciudadano en una realidad multicultural y plurilingüística en los contextos paradójicos de la enseñanza pública. Hay que colisionarse teoría y práctica pues, en cada caso particular de aprendizaje, es importante tener la experiencia como profesor para que se pueda gerenciar los procesos enunciativo-discursivos y las paradojas existentes en ese contexto.

González (2014, p.39) lista tres aspectos fundamentales en la formación del profesor de lengua extranjera: a) "buen desempeño en la lengua que enseña", b) conocimiento sobre la lengua que enseña y c) "ejercicio de la crítica, de la libertad y de la autonomía”. Para alcanzar esa finalidad, es necesario construir un conocimiento teórico sobre la lengua y sobre las teorías lingüísticas y metodológicas como punto de partida y, posteriormente, ejercitar la mirada sensible hacía la materialidad lingüística y sus análisis. Desde el punto de vista metodológico y didáctico, también es básico poseer conocimientos consistentes sobre los principales postulados y, a partir de un análisis del contexto educacional de la comunidad y de las características de cada grupo de alumnos, el profesional debe esbozar un plan de acción que contemple las etapas de pre introducción, desarrollo y evaluación formativa de la dinámica en el aula.

La sistematización de todos esos aspectos constituye un proceso largo y constante que implica, como destaca Perrenoud (2002), formar individuos capaces de desarrollarse, de aprender según la experiencia, lo que suscita una reflexión sobre sus preferencias con relación al hacer, sobre lo que se hizo y sobre los efectos de tales acciones:

O desafio é ensinar, ao mesmo tempo, atitudes, hábitos, savoir-faire, método e posturas reflexivas. Além disso, é importante, a partir da formaçấo inicial, criar ambientes de análise da prática, ambientes de partilha das contribuiçôes e de reflexão sobre a forma como se pensa, decide, comunica e reage em sala de aula. Também é preciso criar ambientes que podem ser os mesmos - para o profissional trabalhar sobre si mesmo, trabalhar seus medos e suas emoçóes, onde seja incentivado o desenvolvimento da pessoa, de sua identidade (PERRENOUD, 2002, p.18).

De ese modo, el proyecto PIBID Letras / Español proporciona un espacio de discusión y (re)construcción sobre el español, al desafiar a los estudiantes en formación que dejen "sua profissão de aluno para se tornarem atores de sua formação e que aceitem formas de envolvimento, de incerteza e de complexidade que podem, com razáo, aterrorizar, aqueles que se refugiam no saber" (PERRENOUD, 2002, p.18).

Tener la conciencia de qué es enunciarse como alumno, de qué es enunciarse como profesor de español en lengua extranjera (E.L.E.) y, a partir de ello, ir construyendo el 
saber qué diferencia un proceso del otro conforme las condiciones de producción que se presentan es un reto imponente. No es suficiente estar en las clases en la universidad discutiendo teorías y metodologías. Tampoco es suficiente ingresar en las prácticas, siguiendo los ejemplos que ya existen. Estas actitudes extremadas no permiten elaborar una visión realista, ética y eficaz sobre los hechos. Es más, puede influenciar a los estudiantes de graduación a que no ingresen en la experiencia docente o que lo hagan de forma que muy pronto se resignen con las circunstancias, se conviertan en un profesional automatizado que trabajan solo para sobrevivir a las cuestiones burocráticas. La mayoría se olvida de la implicación principal de la docencia: la labor "con" y "por" el otro con la finalidad de auxiliar la formación de los demás miembros de la sociedad, lo que permite, consecuentemente, que uno, como pueda, aporte su contribución para modificar la realidad en que se insiere, con efectos que huyen a nuestro control.

\section{Práctica reflexiva docente: el resignificarse en la experiencia y por la experiencia.}

Tras considerar la importancia del sujeto marcarse en el lenguaje, enunciándose y recriando su imagen discursiva como docente, otro punto esencial para que uno se construya como profesor en lengua extranjera es saber observar la realidad de la enseñanza y resignificar las experiencias. Intentar vivenciarlas desde otras perspectivas, a lo mejor, es una de las acciones más costosas a la vez que es una de las más gratificante del profesional que ejerce la enseñanza de algún campo de conocimiento. En lengua extranjera, esa visión desde otros puntos de vista toma una mayor proporción.

En ese trabajo, entendemos el concepto de resignificación de experiencia docente como un proceso en que el individuo observa una experiencia didáctica con una mirada perspicaz, analiza los hechos a partir de cuestionamientos y del contexto específico de la situación y, posteriormente, imprime otras interpretaciones y otros sentidos que permiten la tomada de una posición más crítica y reflexiva con relación a los cambios que deben ser tomados para el perfeccionamiento de esa experiencia. Tal proceso resulta de tres ejes: 1) la (re)lectura y (re)discusión de nociones teóricas; 2) la interlocución entre todos los involucrados en la experiencia, en especial los estudiantes en formación, profesionales formados y tutores y 3 ) la actitud de (co)responsabilidad y proactividad.

El primer eje, la cuestión teórica, se refiere al justo lugar del estudio de la teoría en la formación docente. En el caso del E.L.E., las teorías lingüísticas, literarias, pedagógicas, entre otras, son indisociables de la práctica, como ya enfatiza González (2014, p.3839):

Una práctica teóricamente fundamentada, cuando estamos hablando de enseñanza de lenguas, supone, a mi modo de ver: tener, por lo menos, una concepción clara de lo que es una lengua y ser coherente con ella; tener un concepto de gramática [...] tener claro, entre tantas cosas, lo que es un género, un texto, el discurso, porque 
todo ello es lo que nos permite comprender e interpretar cada texto a partir de sus condiciones de producción [...]; además, hace falta una interpretación clara, y acorde con lo que asumimos sobre los elementos anteriores, de lo que es aprender/ adquirir una lengua, su gramática y todo lo demás que la configura, de lo que puede ser constituirse como sujeto en una lengua. La comprensión de todo ello es indispensable para garantizar la mayor coherencia posible con esos presupuestos en nuestra conducta diaria de profesores e incluso para practicar, deliberadamente, cierto grado de incoherencia.

Por lo tanto, las teorías nos ofrecen un punto de partida para que el profesional se posicione en el momento de observar un fenómeno lingüístico, describirlo, analizarlo y elaborar hipótesis interpretativas. Antes de ser visto como "dogma de fé" para ser defendido, la noción teórica nos da una perspectiva, que puede ser aceptada o rechazada de forma parcial o no. Es un lugar provisorio, pero esa inestabilidad permite que el profesional docente desarrolle constantemente su visión analítica y metodológica sobre el funcionamiento linguístico, característica primordial para construir autonomía en la acción. El profesor no debe(ría) ser un "aplicador de metodologías", desarrolladas por investigadores. Ello contribuye para una cisión entre las prácticas realizadas en las universidades y en las escuelas que, a propósito, nunca debería existir.

El segundo eje, la cuestión de la interlocución, se vincula a la importancia de un cuestionamiento objetivo y claro sobre las expectativas, dificultades, posibles intervenciones en el ambiente escolar. Sin embargo, tal interlocución solo es posible si se configura un grupo en que hay empatía en el sentido de que uno se ponga en el lugar del otro y con la mirada del otro sobre determinada situación. Es realizar un esfuerzo para entender como el otro actuaría en aquel momento para, posteriormente, poder sugerir una solución más adecuada al problema.

Se presentan muchas "fórmulas", "planes" y "estrategias" de actuación, pero no se considera la posición de los individuos involucrados en las circunstancias relacionadas a la rutina docente. Este aspecto es uno de los más problemáticos en cualquier trabajo colectivo porque inviabiliza la visión de grupo, de que hay un conjunto de personas que trabajan en pro de un objetivo en común. En este contexto, es muy importante prepararse para afrontar diálogos difíciles, pues no está en juego probar la verdad o la razón de algo o alguien, sino desarrollar las percepciones de los hechos, los sentimientos involucrados y las identidades amenazadas.

Para construir un trabajo colectivo ante un reto, es esencial ejercitar una postura dialógica que, de acuerdo con las discusiones de Stone, Patton y Heen (2011), significa articular: 1) percepción de la subjetividad de los involucrados; 2) elaboración de un significado y de sentidos comunes; 3) construcción de nuevas perspectivas de la realidad; 4) fortalecimiento de los vínculos; 5) observación del proceso de pensamiento de los miembros del grupo; 6) elaboración de grupos de proyectos de intervención y 7) atenuación de actitudes automáticas y posturas cartesianas. Poner en práctica todos 
estos aspectos es algo que necesita tiempo y serios propósitos de aprender a hablar y a escuchar activamente. En suma, la interlocución es entendida aquí como establecer diálogos que objetivan fortalecer lazos, identificar y cuestionar posturas rígidas y profundizar percepciones sobre las situaciones y los relacionamientos.

Todo lo anteriormente expuesto está relacionado con las posturas y actitudes que los futuros profesionales docentes deben desarrollar en su práctica, una vez que se trabaja íntimamente con la formación del otro, pero, para ello, está implícito cuidar conscientemente con la propia formación en todas las áreas (teórica, pedagógica, personal, entre otras). Educar es profundizar una mirada abarcadora y sutil sobre los hechos y las personas. Al recordar las palabras de Morin (2011, p.13) cuando se refiere a los siete saberes imprescindibles a la Educación del futuro, vemos que el filósofo defiende, enfáticamente, que es básico reconectar los diferentes saberes, pues:

A humanidade precisa de mentes mais abertas, escutas mais sensiveis, pessoas responsáveis e comprometidas com a transformação de si e do mundo. É fundamental criar espaços dialógicos, criativos, reflexivos e democráticos capazes de viabilizar práticas pedagógicas fundamentadas na solidariedade, na ética, na paz e na justiça social.

Se alcanzará tal meta, si se articulan las áreas de conocimiento de modo interdisciplinar, en que se enfoquen siete saberes fundamentales: el estudio de las características y límites del conocimiento; el estudio de los principios del conocimiento pertinente; el estudio de la condición humana; el estudio de la identidad del género humano; el estudio del desafío de las inseguridades; el estudio de la comprensión y, finalmente, el estudio de la ética del ser humano.

Al pensar sobre la enseñanza de la lengua extranjera, en especial del español para brasileños, en el contexto de los siete saberes preconizados por Morin (2011), podemos construir intervenciones en las clases de español que objetiven la discusión entre modos de comprender los demás. Es importante ejercitar la paciencia de observar y escuchar activamente el otro y su perspectiva antes de que uno se posicione, lo que exige flexibilidad y el encontrarse en la mirada y en el lugar del otro. De ese modo, relacionar los contextos sociales, históricos, culturales y económicos de las sociedades brasileñas e hispanas, nos permite recurrir un camino de sutilezas entre las transparencias e identidades que dialogan para exigir el reconocimiento de la singularidad. Es el acercamiento y la cooperación por medio del respecto por la idiosincrasia del diferente.

O outro não apenas é percebido objetivamente, é percebido como outro sujeito com o qual nos identificamos e que identificamos conosco, o ego alter que se torna o alter ego. Compreender inclui, necessariamente, um processo de empatia, de identificação e de projeção. Sempre intersubjetiva, a compreensão pede abertura, simpatia e generosidade (MORIN, 2011, p.82). 
Nuevamente surge un término clave para ese trabajo: la intersubjetividad. En otras palabras, en el lenguaje, el "yo" solo existe cuando se dirige hacia un "tú" y ese "tú" surge por medio de las palabras de un "yo". Es la naturaleza del lenguaje. Cuestionar cómo esas emergencias se dan en el portugués de Brasil y en el español es uno de los aspectos que más contribuirían para la formación del individuo en las clases del español. A partir de este punto, se abre la posibilidad de debatir cuestiones culturales.

Discutir el aspecto cultural es otro punto importante, una vez que es la oportunidad de ubicar el aprendiz de lengua extranjera como ser activo de criticidad e interpretación. Muchas veces, la cultura se limita a ser un aspecto motivacional o es empleada como subterfugio para iniciar un trabajo con estructuras gramaticales. Sin embargo, al pensar sobre determinada manifestación cultural, los sujetos pueden cuestionar su vínculo con los demás y con la naturaleza a partir de determinados lugares. Una vez más uno tiene la posibilidad de ejercitar la empatía y ponerse en varias perspectivas y lugares. De ese modo, estamos de acuerdo con Nardi (2010, p.397) cuando enfatiza que:

[...] a cultura deve ser vista, portanto, como um lugar de interpretação. Assim compreendida, seu estudo se torna, no ensino-aprendizagem de segunda lingua, um momento propicio de promoçáa de deslocamentos capazes de possibilitar que o aprendiz venha a pensar nos processos discursivos produzidos na língua do outro e no modo como nesses discursos os sentidos são produzidos. Passa-se, assim, do simples registro de um imaginário sobre o outro para o questionamento de sua cristalização, o que implica afastar-se da compreensáo da pluralidade cultural como um espetáculo de variedade [...].

Trabajar didácticamente a partir de las manifestaciones culturales, además de referirse al estudio de la comprensión, puede vincularse también a los saberes morinianos de identidad, de condición humana y de afrontar las inseguridades, puesto que es inevitable mencionar la cuestión de pluralidad. Como ya discutimos en otros trabajos, referirse a la cultura es explicitar lo plural en lo tocante al discurso y a la lengua, lo que implica concebirlo como el movimiento de ponerse en el lugar del otro para, posteriormente, volver a ponerse en su lugar de forma más consciente y reflexiva, lo que desencadena una perspectiva de flexibilidad y empatía con relación a lo diferente que se ubica fuera y dentro de uno mismo. La pluralidad es un lugar de construcción e intercambio de vivencias y, por ello, también es un lugar de movimiento y de reflexión.

Por último, en lo que se refiere al tercer eje, la (co)responsabilidad y la proactividad son actitudes en que la articulación del grupo es imprescindible, a pesar de que son aspectos muy difíciles para que sean incorporados en un equipo. En general, existe la tendencia de que uno intente no responsabilizarse por las consecuencias negativas de una situación, al culpar los demás o las circunstancias. Con todo, una acción reflexiva 
debe incentivar la (co)responsabilidad, es decir, cuando cada uno en una agrupación ambiciona traer la responsabilidad para sí y, de este modo, desencadena respuestas con resultados.

Segundo Cordeiro (2013), las circunstancias forman parte de lo incontrolable en una determinada situación. Ahora bien, se puede controlar la forma cómo reaccionamos ante los hechos. De esa manera, es necesario orientar las acciones a partir de dos cuestiones: ¿Cómo puedo contribuir para solucionar tal problema? ¿Cómo puedo hacer la diferencia para mejor? En ese sentido, es aconsejable elaborar buenas preguntas que nos hacen buscar respuestas innovadoras y no soluciones ya convencionales. Ello es una actitud que se espera del profesor en el contexto de la educación brasileña actual.

La (co)responsabilidad implica otra actitud: la proactividad. Mostrarse responsable de las elecciones, independientemente de las circunstancias. La persona proactiva se preocupa en realizar su colaboración, además de auxiliar los demás en sus contribuciones. Para ello, es básico enfocar en las soluciones del problema, en las necesidades del grupo $y$ en el perfeccionamiento continuo individual y colectivo.

Ejercitar estas dos virtudes relacionales es imprescindible en la docencia no solo en el ámbito profesional, sino como forma de desarrollo personal de los docentes y discentes. Creemos que posiblemente es uno de los procesos más difíciles de ser incorporados en un grupo. En la realidad actual, la mayoría de los contextos incentivan el individualismo y el materialismo, aunque hay innumerables iniciativas que promueven pensamientos y actitudes colectivas, solidarias y reflexivas.

Después de todo lo comentado, abogamos que es basilar iniciar los profesores en formación en el proceso de construcción de una actitud reflexiva por medio de la resignificación de experiencias y del análisis del funcionamiento lingüístico con la finalidad de sensibilizar la percepción sobre la emergencia del sujeto en el lenguaje y su naturaleza intersubjetiva. Desarrollar ese proceso supone iniciativas complejas que involucren gestores de varios ámbitos administrativos, docentes, discentes y toda la comunidad que participe de cualquier acción educacional.

\section{El escenario: el subproyecto PIBID Letras / Español en la realidad santamariense.}

En ese momento, es importante que se manifieste un cuestionamiento: ¿cómo se puede concretizar en posturas e intervenciones el proceso de reflexión docente y resignificación de las experiencias? En todo Brasil, existen proyectos que pretenden alcanzar esa meta y uno de estos es el Programa Institucional de Bolsa de Iniciação à Docência, una acción del gobierno federal hacia la valoración de los cursos superiores de formación docente (Licenciatura). De acuerdo con Neves (2014), tal programa tiene como objetivos: 
- la participación en experiencias innovadoras e interdisciplinares;

- la integración entre Universidad, Escuela y Comunidad;

- la articulación entre enseñanza, investigación y proyectos de extensión universitaria;

- la elaboración de intervenciones a partir de la identificación de problemas concretos de la rutina escolar;

- el incentivo a los profesores en formación y a los profesores en ejercicio para que renueven su práctica docente.

La "Universidade Federal de Santa Maria” (UFSM/RS) se incorporó al programa, presente en más del $90 \%$ de los cursos de "Licenciatura" de la presente institución. Uno de los cursos que ha manifestado interés es el de Licenciatura en Letras / Español que, en 2014, tenía un equipo aproximado de nueve universitarios, una profesora supervisora y una coordinadora y profesora del curso de Letras/ Español. La actuación del equipo tuvo lugar en la escuela de educación básica Profa Margarida Lopes y abarcaba los alumnos de la Enseñanza Fundamental y la Media.

La primera etapa consistió en combinar la lectura y la discusión sobre temas básicos del español como enseñanza / adquisición de lengua extranjera, el trabajo con la expresión escrita y la expresión oral en español y la perspectiva constrastiva portugués / español. Pensar sobre algunas nociones básicas sobre lengua, lenguaje, aprendizaje y cómo estas nociones podrían convertirse en base para elaboración de la propuesta ha sido un proceso costoso e intenso en el ejercicio de ubicarse como alumno de graduación y como profesor. Además, se propició un momento de estudio sobre la realidad escolar. En este sentido, recordamos las palabras de Perrenoud (2002, p.171) al comentar sobre el sentido y las finalidades de la escuela:

Nenhum formador de professores pode ignorar o problema das finalidades da escola e de seu sentido. Somado a isso, não pode resolvê-lo, pois ele está no centro das contradiçóes do sistema educativo e da intenção de educar e instruir: contradiçôes entre o desejável e o possivel, entre as promessas e os atos, entre as belas idéias e as resistências à realidade, entre as aspiraçôes democráticas e os mecanismos de exclusão.

Por otra parte, se ha destacado el papel del profesor también como el de investigador por medio de la necesidad de registrar las actividades y de divulgar los resultados. En tal punto, surgió el reconocimiento de la relevancia de los géneros académicos (resúmenes para eventos, artículos, diapositivas para presentaciones, etc.), así como lo imprescindible que es crear un proyecto de texto para manifestar un discurso coheso y coherente, todo ello en el contexto de las dos lenguas. Al referirse sobre la formación del profesor, González (2014, p.24-25) manifiesta, de forma vehementemente crítica, una serie de indagaciones sobre la investigación teórica y su lugar en la formación: 
Ahora bien, ¿̇hasta qué punto reconocemos que la labor docente no es un lugar secundario, donde solo se ponen en práctica (conscientes o no) ideas de grupos de elite, sino ese momento fundamental de investigación experimental que hará que las teorías se muevan y avancen? ¿Hasta qué punto estamos teniendo en cuenta ese proceso cíclico, esa fuerte relación de interdependencia, podríamos decir, entre teoría y práctica, esa dinamicidad y esa complejidad cuando concebimos la formación del profesor? Al contrario, la palabra de orden que muchas veces se escucha es "simplificar", en gran parte para atender a la urgencia [...] Pero se puede preguntar: ¿¿no se está confundiendo simplificar con reducir? ¿En realidad, no se estará mistificando?

Nos damos cuenta en las discusiones del grupo PIBID que el primer obstáculo es amenizar la actitud demasiadamente imediatista que corrompe la didáctica de la lengua extranjera (¿Cómo enseñarle X a este grupo y terminar el programa en el tiempo establecido?) que procede de la dinámica y del lugar que el español ocupa en la escuela pública. Antes, es fundamental buscar una argumentación coherente del porqué se aplica tal metodología en ese contexto, vinculada a algunas teorías del lenguaje, a algunos conceptos claves de cómo se entiende la lengua, el enseñar el español, el papel del español en la formación del ciudadano brasileño de determinada región. Más que ofrecer respuestas parcialmente seguras, el proyecto se propone a sembrar preguntas y a desconstruir paradigmas. Oscurecer para, posteriormente, aclarar algunos caminos...

En ese contexto, se presenta un segundo bloque de lecturas que objetiva ubicar la cuestión del español en la enseñanza de la escuela pública. Por lo tanto, la discusión sobre los "Parâmetros Curriculares Nacionales", las "Orientaçóes Curriculares para o Ensino Médio”, el "Projeto Político e Pedagógico" de la escuela viene a complementar el esbozo de aspectos relevantes que se debe llevar en cuenta cuando uno pretende construir una postura docente como profesor de español en determinada escuela. Se debe observar atentamente el espacio en que el profesional de la docencia va a actuar.

En este punto, las dificultades y dudas ya amenazaban el ánimo de muchos integrantes, lo que motivó volver a lecturas y a discusiones sobre qué sería el PIBID y por qué estar en ese proyecto. Es decir, ello significa que uno debería construir una visión sobre su formación docente, sobre su curso de graduación y sobre la elaboración de un ethos del profesor deseado, al considerar las potencialidades y límites que cada circunstancia nos ofrece. Estábamos dedicando esfuerzos para la elaboración de un proyecto común con objetivos claros en que los vínculos fuesen más amplios y significativos que la cuestión administrativa de realizar algunas tareas para que le otorguen al estudiante una beca. Cuestiones sobre ética profesional, formación del ciudadano y (co)responsabilidad en mi formación y la del otro fueron temáticas recurrentes a partir de aquel momento. De ese modo, trabajar la noción de 
ethos docente fue una manera de trabajar la construcción de la imagen discursiva del profesor y su importancia, lo que enlazó teoría y práctica.

En la segunda etapa, después de muchos intercambios de posiciones, el equipo identificó como prioridad de acción en la escuela en que estaban el problema de la percepción de sí y del otro. Ese tema conlleva un enfoque multidisciplinar e interdisciplinar, en que saberes circulan, se sobreponen y se reorganizan para analizar y construir una perspectiva de un determinado tema o problema en toda su complexidad.

De esa forma, se ideo una exposición, posteriormente bautizada como "Olhares Essenciais”, en que grupos de alumnos de la Enseñanza Fundamental y Media producían sus microcuentos en español a partir de fotografías realizadas en su cotidiano. Para lograr tal conjunto, el equipo ha trabajado y ha articulado las nociones de "género textual", "microcuento" e "instante decisivo", conceptos respectivamente del área de la Lingüística Textual, de la Literatura y de la Fotografía.

Es primordial mencionar que el título de la exposición ya apuntaba hacia la valoración de elaborar una mirada sensible a la experiencia, a la realidad y al otro. Es diferenciar lo esencial de lo secundario o de lo superficial. Por otro lado, la propia actividad distinguía la intersubjetividad del momento irrepetible de la enunciación (la captación del movimiento, por ejemplo) y las marcas que habían en el enunciado (la fotografía) que, a su vez, creaba condiciones para la producción de nuevas enunciaciones y sus respectivos enunciados (los microcuentos). Por supuesto que todas esas diferencias e hipótesis han sido elaboradas a posteriori, pero ello forma parte del proceso de maturación docente.

Nos gustaría destacar la noción fotográfica de "instante decisivo", concebida por el padre del fotorreportaje, Henry Cartier Bresson (1908-2004), uno de los fotógrafos más renombrados del siglo XX y co-fundador de la agencia fotográfica Magnum. Como esboza Badger (2009, p.104), el "instante decisivo" es la fotografía que capta:

[...] el momento importante en el flujo constante de la vida y lo capta en una fracción de segundo [...]. De hecho, el momento decisivo se define mejor como el instante en que forma y contenido se unen para crear una imagen cuyos elementos formales, emocionales, intelectuales y poéticos tienen sustancia, es decir, que le confieren un significado real.

En otras palabras, estamos de acuerdo con Nates (2011) que es la fotografía, cuyo protagonista es el movimiento, en que hay un tiempo, un espacio y un motivo, lo que puede formar una secuencia narrativa con función dramática. El propio Cartier Bresson ilustra ello en Detrás de la estación de Saint-Lazare (1932): 
Figura 1 - Detrás de la estación de Saint-Lazare (1932)

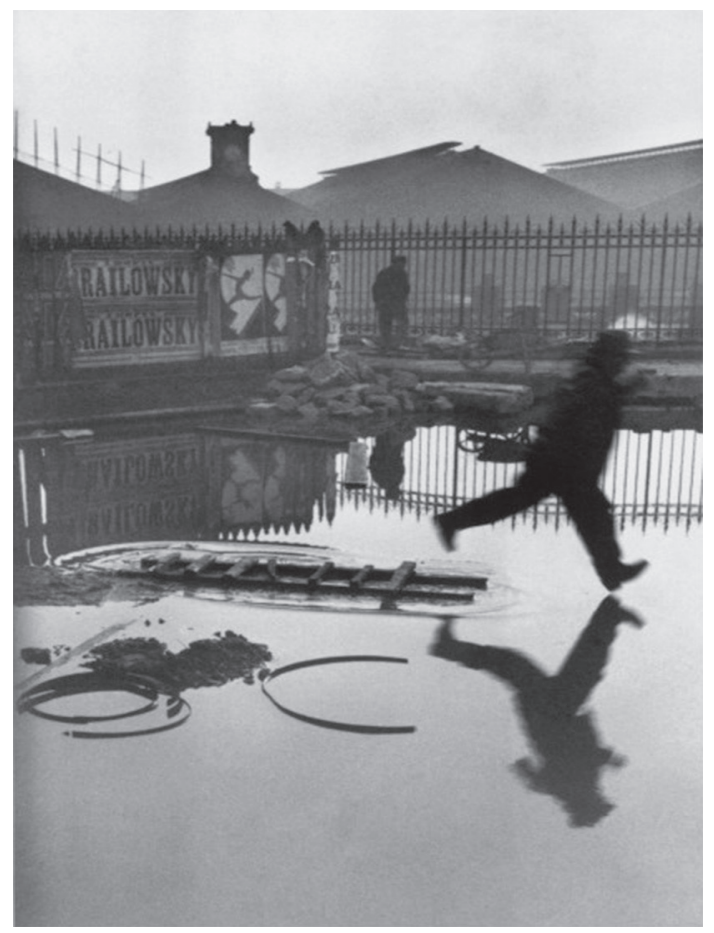

Fuente: Nates (2011).

Como podemos deducir, además de poder trabajar el contexto histórico y cultural de una de las fases más importantes del siglo XX relacionada al recurrido profesional de Cartier Bresson, con el concepto de "instante decisivo" se ha podido discutir algunas cuestiones filosóficas y sociológicas tales como la elaboración de una perspectiva, algunos conceptos de la "realidad", lo efémero versus lo eterno, el punto de vista sobre un hecho, la creación narrativa en la imagen y en la escritura, entre otros.

Ese último punto ha sido propicio para vincular el tema de cómo el sujeto puede observar e interpretar la realidad con las manifestaciones literarias, en especial en lengua española, una vez que uno de los ejemplos más célebres de microcuento - "El dinosaurio" - viene del escritor gualtemalteco Augusto Monterroso (1921-2003), publicado en "Obras Completas (y otros cuentos), en 1959: "Cuando despertó, el dinosaurio todavía estaba alli’. La noción de unidad mínima narrativa que provoca el máximo de impacto y efectos de sentidos combina perfectamente con la idea de énfasis al instante ínfimo de movimiento. 
Al considerar los objetivos de la enseñanza de una lengua extranjera en la escuela pública y el énfasis de una perspectiva enunciativo-discursiva del español, optamos por ese enfoque de conjunción entre sujeto, lengua y arte debido al hecho de que las manifestaciones artísticas pueden ser un instrumento terapéutico en la medida de que pueden convertirse en un guía de autoinvestigación para los cuestionamientos existenciales como defienden Botton y Armstrong (2014). Según esos filósofos, el arte posee siete funciones terapéuticas: rememoración, esperanza, sufrimiento, reequilibrio, comprensión de sí, desarrollo humano y apreciación. Por lo tanto, la perspectiva terapéutica se ańade a las demás maneras de valorar el arte como una visión técnica, política, histórica y contestadora.

Ha sido un largo recorrido para que los alumnos de la Enseñanza Fundamental y Media comprendieran la esencia de los dos conceptos, así como fue complejo, e igualmente trabajoso, que el equipo percibiera las principales interrelaciones entre estos conceptos y la cuestión de percepción de sí y del otro, de marcarse en una materialidad (lingüística y/o imagética), la subjetivad en el lenguaje, la (re)creación de un hecho. Todo ello traspasando el estudio de la lengua española y la integración suya con el contexto de las demás asignaturas y con los temas pertinentes a la comunidad y a cada uno de los individuos involucrados en la experiencia. Frecuentemente, los integrantes reducían el conjunto a las nociones de "realizar fotografías que contengan movimientos" y "escribir narraciones con menos de tres líneas".

Otro aspecto problemático se refiere a cómo trabajar didácticamente con tal tema, considerando las limitaciones del tiempo de las clases y de la logística de la escuela. Es más, cómo articular y realizar una muestra fotográfica en que los alumnos fotografiasen escenas de su cotidiano a partir del principio del "instante decisivo" y, posteriormente, redactasen un microcuento, en español, inspirados en esas imágenes.

Varios factores han dificultado el trabajo: la diferencia de motivaciones entre sacar las fotos y elaborar los cuentos; los conocimientos parcos de la expresión escrita en español (y también en portugués en algunos casos), la logística para recoger fotos y cuentos; combinar cuentos y fotos, entre otros. Incluso, como estrategia para influenciar el grupo y entender la dinámica de la tarea, todo equipo pibidiano (profesora coordinadora, profesora supervisora y alumnos becarios) ha tenido que sacar una foto y elaborar su microcuento. 
Figura 2 - Una de las fotos de la exposición

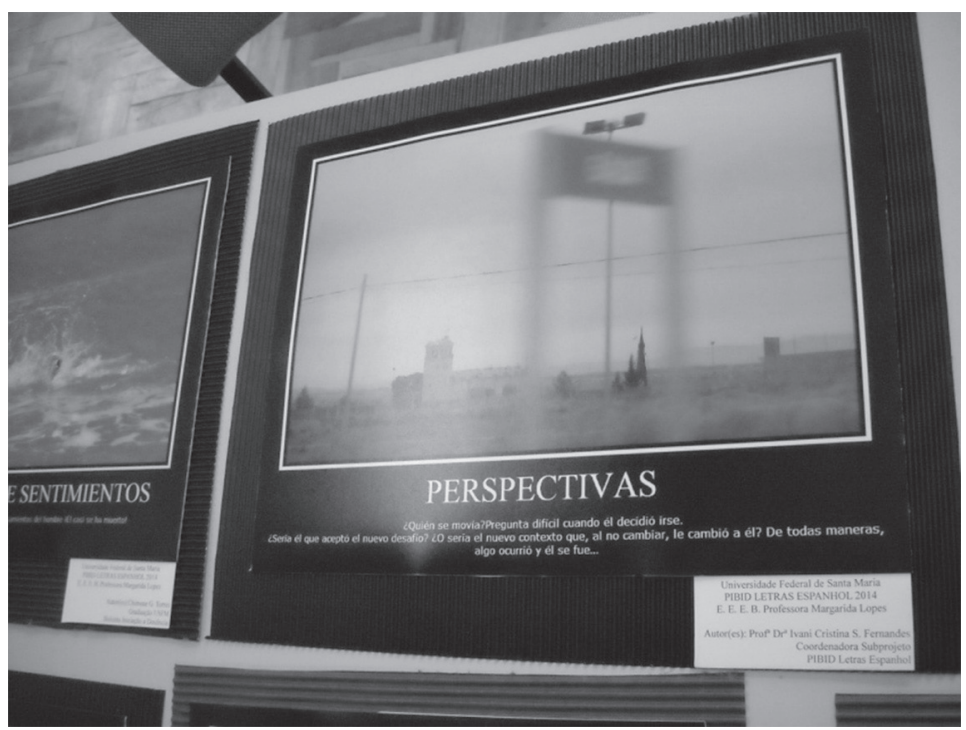

Fuente: Arquivo pessoal PIBID Letras / Espanhol 2014.

Ha sido un modo de observar, vivenciar y resignificar la experiencia desde una perspectiva externa (como mediadores de las tareas) y desde una perspectiva interna (como más un sujeto que formaba parte de la experiencia). También se ha vivenciado la teoría de enunciarse en una determinada materialidad, pues no siempre el proceso de discutir la teoría y colocarla en práctica fue linear. La redacción de la presentación de la muestra ha representado una oportunidad de revaluar la actividad y explicitar para el grupo cómo las bases teóricas pueden estructurar la teoría e/o cómo la práctica puede cambiar la visión sobre determinada teoría. Además, ha sido otra forma de fortalecer el equipo alrededor de un objetivo común.

Sin embargo, todos esos obstáculos fueron testes para ejercitar la (co) responsabilidad y la articulación entre teoría y práctica en circunstancias recurrentes en la escuela pública. Las fases de montaje de la exposición, en varios ambientes, también ha creado una ocasión para negociar objetivos y sentidos, para vivenciar las limitaciones de recursos de todos los ámbitos, para proponer alternativas delante de imprevistos, etc. 
Figura 3 - Organización de las fotografías

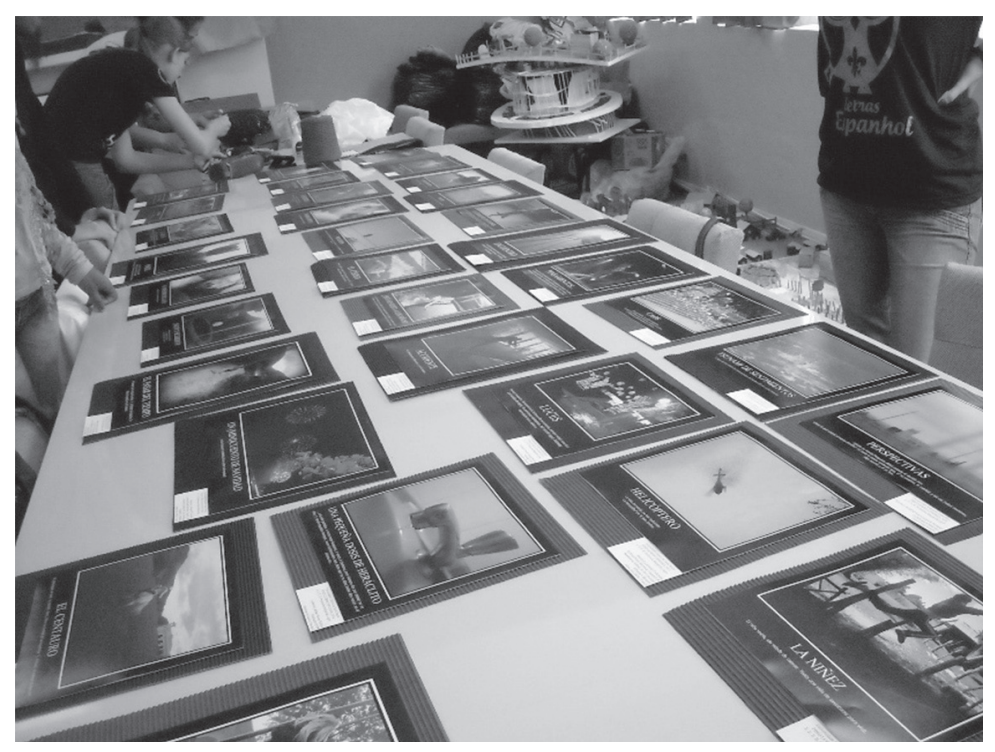

Fuente: Arquivo pessoal PIBID Letras / Espanhol 2014.

Además de la comunidad santamariense y escolar, se ha presentado la exposición en varios eventos académicos, talleres para profesores y eventos relacionados con otros subproyectos del PIBID. Han sido vivenciadas concepciones muy presentes en las Orientaciones Curriculares - alteridad, diversidad y heterogeneidad - en que mediadores también fueron mediados por la propia experiencia al surgir como agentes de (co)construcción de saberes.

De esa manera, tal contexto ha propiciado evaluaciones constantes de los resultados y, principalmente, del proceso, lo que ha influenciado la manera cómo todos construyen la percepción sobre la actividad docente, el modo impar de trabajar el funcionamiento de la lengua española y la subjetividad en el lenguaje. Por otro lado, recordando las funciones terapéuticas del arte preconizadas por Botton y Armstrong (2014), enfatizamos que tal actividad, que incentiva la manifestación artística y la percepción de sí y del otro, se ha convertido en un guía de autoconocimiento, de ampliación de experiencias y de revitalización de sensibilidad. 
Figura 4 - La exposición montada en la "Praça

Saldanha Marinho", en Santa Maria (RS)

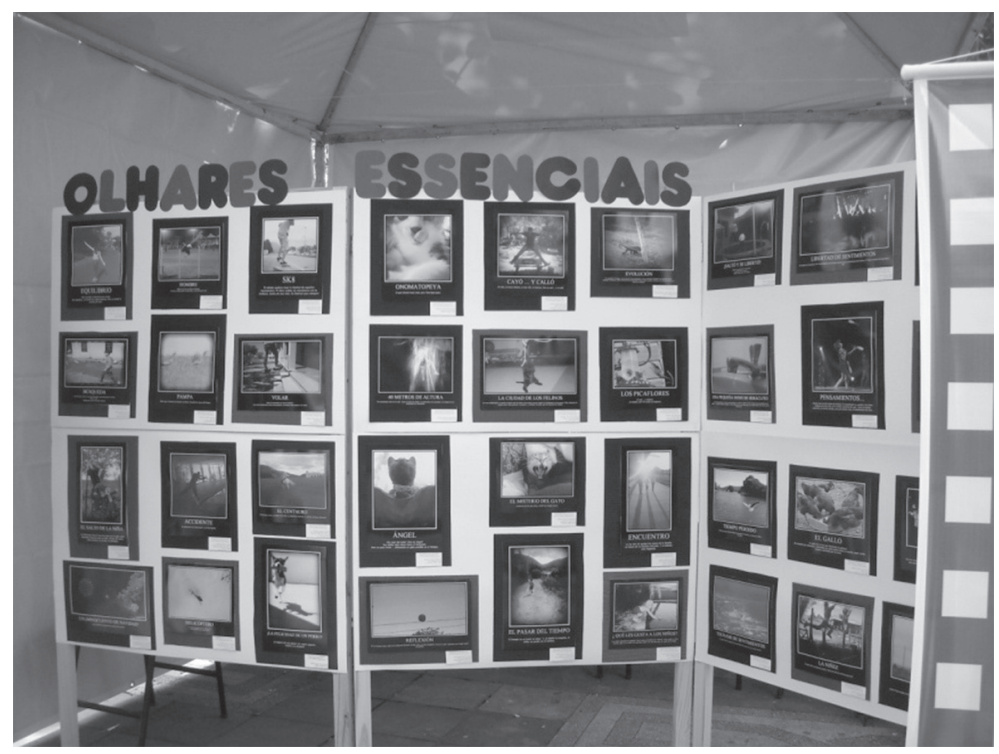

Fuente: Arquivo pessoal PIBID Letras / Espanhol 2014.

Todos esos procesos de resignificaciones y enunciaciones de sí y del otro han ocasionado algunos cambios primordiales en el modo de ver la docencia y el proceso de formación. Conforme los principales efectos que tal actividad provocó entre los integrantes, podremos dividirlos en tres grupos: profesor en formación, profesor ya formado, profesor- formador.

En primer lugar, los profesores en formación, es decir, los alumnos de la "Licenciatura", han creado un espacio propicio para la reflexión sobre la profesión docente, lo que ha despertado la necesidad de integrarse a actividades de investigación, enseñanza y extensión universitaria. Además, la gran mayoría ha pasado a ver, de un modo más crítico, su curso de "Licenciatura" y su actuación en las clases y en sus elecciones de las asignaturas. Están haciéndose (co)responsables de su formación en lugar de ser un alumno pasivo que sigue automáticamente el curso. Todo el conjunto de la "Licenciatura" se beneficia de esta nueva postura, una vez que los alumnos que no están integrados en el proyecto son influenciados por las palabras y ejemplos de los becarios. Metafóricamente, están enunciándose como futuro profesores.

En segundo lugar, con relación al profesor supervisor, se le ha posibilitado la revisión y resignificación de su práctica, una vez que el contacto con las discusiones teóricas y con visiones de otros individuos que están en lugares distintos en la formación permitió valorar la actuación del profesor supervisor a la vez que se le ha despertado la necesidad de perfeccionamiento constante. A pesar de la dinámica escolar no siempre 
adecuada al proceso de formación, el profesor-supervisor comprende que es posible construir una postura más activa y que valore su profesión y su papel en la comunidad escolar y en el trabajo colectivo. Además, pasa a entender mejor la importancia de explotar el funcionamiento de la lengua, considerando lo enunciativo y lo discursivo y las vinculaciones de ello con la alteridad y la heterogeneidad.

En tercer lugar, referente a la figura del profesor coordinador, la experiencia también ha propiciado una resignificación sobre lo qué significa formar profesores de español como lengua extranjera y, como consecuencia, revisar la forma de articular teoría y práctica en las clases de "Licenciatura". Como destaca Perrenoud (2002), el profesor-formador debe tener una mirada atenta hacia la formación reflexiva a partir de las necesidades prácticas y de los problemas encontrados. Negociación de procedimientos y contextos, proyectos adaptados a las circunstancias, enfoque en el sujeto en formación, postura atenta hacia la autoformación, entre otros aspectos que ese nuevo profesor formador debe ańadir a su postura. Por otro lado, las contradicciones y la fuerza de las negociaciones para incentivar la (co) responsabilidad ha contribuido en otros proyectos de extensión a partir de la reflexión teórica que se da por medio de elaboración de artículos y participación en eventos y talleres.

De todas maneras, los involucrados, directa o indirectamente en el proyecto, han tenido la oportunidad de marcarse en la materialidad lingüística y en la discursividad docente, lo que significa vivenciar el concepto de la intersubjetividad en el lenguaje. Por otro lado, un proceso que ultrapasa los límites de la profesión docente es el de negociar sentidos, el de hacerse (co)responsable por los problemas y soluciones y el de adoptar una actitud proactiva y reflexiva.

\section{Consideraciones provisorias}

Formar parte de proyectos con estas características es una oportunidad de desestabilizar seguridades y rutinas a la vez que nos ofrece la ocasión de sensibilizar nuestra mirada para aspectos sutiles que revigoran la actuación profesional docente así como el propio papel en nuestro recorrido personal y existencial.

No es un proceso agradable durante todo el tiempo. Se puede caracterizarlo como desafiante y costoso, ya que exige el juego continuo entre acercamiento y alejamiento del funcionamiento lingüístico del portugués y del español combinado con una reconfiguración del papel del lenguaje y de su discusión en el ámbito de la enseñanza. De ese modo,

Qualquer razão prática acompanhada de um minimo de distância, de um trabalho de explicitação e formalização da experiência provém do paradigma reflexivo. Portanto, ele se encontra no centro de toda profissáa e das práticas daqueles que, em todos os oficios, contemplam uma eventual profissionalização. 
Ao mesmo tempo, a simples reflexão sobre e na ação tem seus limites: os da tomada de consciência e os das ferramentas teóricas e metodológicas. Para extrapolar uma intenção reflexiva baseada no sentido comum e na inteligência profissional, é preciso passar para uma forma mais sofisticada de análise do trabalho e dos habitus, assim como de análise das competências presentes em toda atividade (PERRENOUD, 2002, p.211).

Aunque provisorias y parciales como deben ser las consideraciones finales de un trabajo, es posible identificar algunas sendas para que uno pueda hacerse un profesional docente competente. En primer lugar, es desarrollar un diálogo contante con la postura analítica y teórica, articuladas conforme cada circunstancia. El profesor de español debería ser un mediador intercultural con una enfática presencia analítica y reflexiva. Además de tener un buen desempeño en la lengua y construir un saber y una visión sobre el funcionamiento de esta lengua, el docente necesita construir una base teórica para poder ejercer su autonomía de manera coherente. Por otro lado, observar los fenómenos lingüísticos a partir de una perspectiva enunciativo-discursiva puede perfeccionar la mirada para otros fenómenos de naturaleza filosófica, sociológica y psicoanalítica, por ejemplo.

Fueron muchos los obstáculos todavía no ultrapasados, finalidades no cumplidas, intervenciones mal sucedidas. Con todo, para este tipo de experiencia, solo la mirada retrospectiva nos permite identificar los avances, redefinir rutas, identificar teorías en la práctica y ver en la práctica la razón de la teoría. En ese sentido, tal trabajo ya es una prueba de ese proceso y colabora para que los formadores, en particular los que se encuentran en las "Licenciaturas", cuestionen si consiguen desplazarse y articular los lugares de profesor, de investigador y de formador en su nicho universitario. En una realidad multifacetada, plural e inestable, reconocer la precariedad de los paradigmas absolutos ante los cuestionamientos analíticos ya es un inicio de una postura más coherente y consciente como docente. Ese profesional debe buscar la articulación del saber relacionado al interdisciplinar y a la complejidad de la esencia humana que deja marcas en la lengua y en el lenguaje, lo que posibilita el surgimiento del sujeto discursivo y de la resignificación de sentidos. Esperamos que esas palabras ya sean una invitación al dialogo y al cuestionamiento.

\section{EMERGING IN LANGUAGE AND THE RESIGNIFICATION OF EXPERIENCES: CONSIDERATIONS ABOUT PIBID IN THE REFLECTIVE TRAINING OF SPANISH TEACHERS IN BRAZIL}

- Abstract: This paper aims at discussing some aspects of reflective practice in Spanish teacher education in Brazil based on the redefinition of experience and on the analysis the subjective marks the discursive subject imprints on the linguistic materiality. This discussion evolves from the work developed in the subproject PIBID Letters/Spanish at the Federal University of Santa 
Maria. Given the notions of the Linguistics of Enunciation and Philosophy of Education devised for the education of ELE teachers, this paper claims that the educator of future teachers should engage in experiences that require theoretical study, and reflective and co-responsible attitudes so as to be able to suggest solutions for recurrent problems in certain educational environments.

- Keywords: Reflective teacher. Enunciation. Spanish language. PIBID.

\section{REFERENCIAS}

BADGER, G. La genialidad de la fotografía: Cómo la fotografía ha cambiado nuestras vidas. Blume: Barcelona, 2009. 256 p.

BENVENISTE, E. Problemas de Lingüística Geral II. São Paulo: Pontes, 2006. 294 p.

BRASIL. Ministério da Educação. Conhecimentos de espanhol. In: Orientaçóes curriculares para o ensino médio: Linguagens, Códigos e suas Tecnológicas. v.1. Brasília: Ministério da Educação, 2006. p.125-164.

BOTTON, A.; ARMOSTRONG, J. Arte como terapia. Rio de Janeiro: Intrínseca, 2014. 240 p.

CORDEIRO, J. Accountability: a evolução da responsabilidade pessoal: o caminho da execuçấo eficaz. São Paulo: Évora, 2013. 132 p.

FIORIN, J. L. As Astúcias da Enunciaçáo: as categorias de pessoa, espaço e tempo. São Paulo: Ática, 2005.

FLORES, V. N. Sujeito da enunciação e/ou sujeito do enunciado? Exterioridade e interioridade teórica no campo da Lingüística da Enunciação. In: MARTZENAUER, C. L. B. et al. (Org.). Estudos da Linguagem: VII Círculo de Estudos Lingüísticos do Sul. Pelotas, RS: EDUCAT, 2008. p.85-104.

FLORES, V. N. et al. Dicionário de Linguística da Enunciaçáo. São Paulo: Contexto, 2009. $288 \mathrm{p}$.

GONZÁLEZ, N. T. M. La reflexión teórica en la formación del profesor, en su práctica y en la producción de materiales. In: CORDEIRO, A. L. et al. (Org.). Hispanismo no Brasil: reflexôes e sentidos em construção. São Carlos: Pedro \& João Editores, 2014. p.17-39.

KULIKOWSKI, M. Z. M.; GONZÁLEZ, N. T. M. Español para brasileños: sobre por dónde determinar la justa medida de una cercanía. In: ANUARIO BRASILEÑO DE ESTUDIOS HISPÁNICOS. n.9. Brasília: Consejería de Educación y Ciencia de la Embajada de España en Brasil, 1999. p.11-19.

MORIN, E. Os sete saberes necessários à educaçáo do futuro. São Paulo: Cortez; Brasília: UNESCO, 2011. $104 \mathrm{p}$. 
NARDI, F. S. Espaços de identificação: um olhar discursivo sobre a cultura em livros didáticos para o ensino de língua espanhola. In: CONGRESSO INTERNACIONAL DE PROFESSORES DE LÍNGUAS OFICIAIS DO MERCOSUL, 1., 2010, Foz do Iguaçu. Anais..., Foz do Iguaçu, 2010. p.395-403. Disponível em: <http://www.apeesp.com.br/web/ ciplom/Arquivos/artigos/pdf/fabiele-nardi.pdf>. Acesso em: 20 jan. 2015.

NATES, O. C. El "instante decisivo" de Henri Cartier-Bresson. 2011. Disponível em: $<$ http://oscarenfotos.com/2011/11/19/el-significado-del-instante-decisivo-de-henri-cartierbresson/\#_edn11>. Acesso em: $10 \mathrm{dez} .2014$.

NEVES, C. M. C. Pibid: integração entre universidade e educação básica: entrevista concedida a Rosangela Guerra. Revista Presença Pedagógica, Belo Horizonte, v.20, n.117, p.5-9, mai./ jun. 2014.

PERRENOUD, P. A prática reflexiva no ofício de professor: profissionalização e razão pedagógica. Porto Alegre: Artmed, 2002. $232 \mathrm{p}$.

REVUZ, C. A língua estrangeira entre o desejo de um outro lugar e o risco do exílio. In: SIGNORINI, I. (Org.). Linguagem e Identidade: Elementos para uma discussão no campo aplicado. São Paulo: Mercado das Letras, 1998. p.213-230.

SCHÖPKER, R. Dicionário filosófico: conceitos fundamentais. São Paulo: Martins Fontes, 2010. $256 \mathrm{p}$.

SERRANI, S. Discurso e cultura na aula de língua: Currículo, leitura, escrita. Campinas, SP: Pontes, 2005. $144 \mathrm{p}$.

STONE, D.; PATTON, B.; HEEN, S. Conversas difíceis: Como argumentar sobre questóes importantes. Rio de Janeiro: Elsevier, 2011. 242 p. 